\title{
THE ROLE OF A STATE-WIDE FOUNDATION IN THE WAR ON POVERTY
}

\author{
Grorge H. Esser, JR.**
}

The "war on poverty" is the most recent step in our search for a more perfect democratic society. Because this war reaches into every aspect of our national life, it requires a perspective broader than any one of us normally employs. It also seeks change on a broader scale than any single national effort.

As the pace of the war quickens, we are becoming more aware of the significance of essential interrelationships-the importance of economic growth for the success of antipoverty programs which must promise jobs; the weakness of the federal system in adapting to programs demanding close and intricate coordination between many federal, state, and local agencies; our middle-class failure to understand the poor of all races, and the resulting failure of our middle-class oriented social institutions to make an impact on poverty; the barriers in our economic, social, and political systems that keep the poor in a never-ending "cycle of poverty"; and the inability of communities to develop processes for defining and meeting the total needs of people in the community.

The North Carolina Fund as a State-Wide Foundation

The North Carolina Fund was established as a small foundation to help North Carolinians find ways to break the "cycle of poverty." The Fund's conception and early history have been covered in the preceding article; that history reached a transition point in the passage of the Economic Opportunity Act of $1964 .^{1}$ At that point the Fund's initial mission, to seek solutions to the poverty problem through community action on a demonstration or experimental basis, was superseded in part by the new federal program.

Fortunately, both the Fund's proposal to its supporting foundations (the Ford Foundation, the Z. Smith Reynolds Foundation, and the Mary Reynolds Babcock Foundation) and the grant letter under which it received funds recognized the broad areas within which the Fund might have to act in seeking its objectives. The Fund's charter established a broad arena for action. It authorized the Fund:

a. To do all things necessary or proper to aid in improving the education, economic opportunities, living environment and general welfare of the people of North Carolina, either directly or through other private or public organizations.

-B.S. 1942, Virginia Military Institute; LL.B. 1948, Harvard University. Executive Director, The North Carolina Fund. Formerly professor of public law and government and assistant dircctor of the Institute of Government at the University of North Carolina.

${ }^{1} 78$ Stat. 508, 42 U.S.C. $\$ \S 2$ jor-981 (1964). 
b. To study the problems involved in improving the education, economic opportunities, living environment and general welfare of the people of North Carolina, of all ages and in different parts of the state; to make and recommend grants for research, pilot experimental and other projects toward the solution of such problems; to make available professional staff services to private and public agencies, both state and local, seeking solutions to such problems; to encourage cooperative state and community action in devising such solutions; and to encourage wise use of public and philanthropic funds devoted to any of these purposes.

The grant letter from the Ford Foundation was more specific but still very flexible. Although it defined the Fund's major responsibility as the provision of support for a "limited number of comprehensive community development projects," it also permitted grants in support of innovative projects on a state-wide basis, and the use of funds in support of planning and technical assistance, education and training, and research and evaluation.

A foundation may act in a number of ways. In purely philanthropic fashion, it may provide the funds needed for a new program or facility. It may provide grants to help other institutions explore new programs or seek to bring about change. In serving as a catalyst, it may provide all of the funds or simply the critical, risk-taking share. But the foundation's function is not limited to grants of money alone. Depending on the situation, on need, and on opportunity, it may itself provide technical assistance to other institutions. It may itself sponsor and administer innovative and experimental programs on a demonstration basis. It may undertake research and evaluation to determine appropriate new directions or the validity of competing alternatives. It may sponsor, directly or indirectly, public information and educational programs. But these are means of acting; they do not define the foundation's role.

The passage of the Economic Opportunity Act of $x 964$, and other legislation aimed at creation of the Great Society, brought millions of dollars to bear on the very problems the Fund was created to support through experimental action. The board of directors of the Fund could not, in good conscience, spend its limited funds for the same programs which now could draw on ample federal resources. But as government takes over responsibility for programs whose need has been defined by foundation projects, the opportunity exists for the foundation to experiment in other areas and to explore new frontiers for action. Within the context of a concern for the problems of the poor in North Carolina, the Fund has sought to fill this sort of role.

If the Fund were an agent of government-either federal or local-its scope would probably be more narrowly defined, though its resources might well be more bountiful. That is, although it might be less limited in the time available to accomplish its objectives, it would be perhaps more limited in its freedom to 
define its roles and to investigate the choices available, and certainly more limited in defining its functions.

But as a foundation entitled to act in a number of ways, it still must act in the context of the possible. Yet, were the Fund to use this freedom merely in a dayto-day "expense of spirit"- use of energy and of funds in reaction to the problems that exist and in conquering the frustrations and limitations implicit in the complexity of government-its contribution to the welfare of people would again be "more of the same." Thus, coupled with its necessity to act within the context of the possible must be a responsible use of the art of the possible. The fact that administration of funds is a science requires that foundations, as public servants, be aware of the context within which they serve, and the most efficient, most valuable, most humanly remunerative use of those funds. The fact that administration of funds can also be an art requires that foundations be creative-that is, that they disturb that context.

The very limitation of time in which to act has to be used creatively. The Fund was financed under grants running for a period of five years, and the board has taken the position that the Fund should regard that period as terminal lest the temptation to institutionalize its functions become too great. The Fund finds itself required by this shortness of intended life to create the possible-in effect to examine the whole fabric of the war on poverty, the holes in imperfect weaving of programs, the knots where the complexity of government has impeded an effective process, the imperfections that signify the need for change. The Fund must point out these imperfections, must provide the assistance necessary to mend the tears, must sometimes accept the imperfect whole, and must sometimes force a reweaving-to join the separate threads of social agencies, or provide the means to change institutions. And at times, if the finished garment does not cover the body of the poor, while allowing the poor to flex their muscles, the Fund must be able, flexible enough, and willing to try to create a new one.

Action within the context of the possible, responsibility for using the art of the possible, and creation of the possible might well be called the roles of the Fund. These roles are not necessarily specific pledges in the proposal to the supporting foundations, but they are in the spirit of that document. The means the Fund must choose to carry out these roles thus flow from its objectives and, when the choice is deliberately and carefully made, determine its functions. The objectives are clear; the functions must vary with time, climate, money, community, and so on, and particularly with the means chosen or created before those functions are determined. It is these means with which we must deal, these choices which must be measured against our objectives, these innovations, if needed, for which we are ultimately responsible.

Although the Fund can extend its activities throughout the state, its initial emphasis on the community as the critical focal point for dealing with the problems 
of poverty has been continued. Before looking at the choices made by the Fund in how to deal with the problems of the poor, it is useful to look at both the opportunities and the limitations implicit in this selection.

\section{The Context of Community}

The definition of "community" for purposes of antipoverty programs may be said to have begun with the concerns of the Ford Foundation "grey area" programs and the projects sponsored by the President's Committee on Delinquency and Youth Crime for the problems of people living in urban slums. The context for action in these projects was usually the political jurisdiction within which action affecting services provided in slum neighborhoods could be planned and implemented. Although the planning and implementation was generally through the new instrument of a non-profit corporation, the cooperation of existing governmental and voluntary agencies at the municipal or county level was essential.

A similar approach was followed in the statement of The North Carolina Fund's initial program, since the county in North Carolina is the smallest unit responsible for administration of educational, health and welfare functions. Administration of the Economic Opportunity Act of 1964 has followed essentially the same approach. While the focus of particular programs may, then, be the neighborhood where the poor live, planning, financing, and administration are through a governmental unit or corporation which can involve the cooperation of the basic service agencies concerned for the poor throughout the community. The definition of community for administrative purposes is therefore pragmatic and includes the flexibility to decentralize particular programs to smaller communities.

The assumption of the "community action" approach is that effective action to deal with the problems of the poor must take place in the community where the poor live and work, and that all the resources of the community-whether public or private, or of local, state or federal origin-can best be mobilized and focused on those who need help where they are. We must, the assumption goes, enlist the cooperation of the total community in examining the total problems of people in the community and in finding solutions built to the particular needs of those people.

The arguments in favor of this approach have much logic. The poor, the slums they live in, the problems of poor health and delinquency and insufficient income, are a reproach to the community. They are a drain on community services and governmental revenues. They are the Achilles' heel of a democratic society. Logic dictates that poverty must be eliminated or the impact of poverty on the community reduced.

Many resources to deal with poverty exist at the community level and within the systems of community power. Many of them were established to deal with poverty. 
The clientele of the welfare department basically consists of the poor. Many of the services of public health departments are aimed at the poor. Most of the services of voluntary welfare agencies are for the poor. And if the answer to poverty is education, then the public school systems and the adult education agencies are directly concerned with the poor.

If something is missing, if we are simply failing to find the right combination to the problems of the poor, then it should be within the capacity of the community to find that combination. Is it more services? Then the answer is to find the resources to support those services. Is it a different type of service? Then the answer is to find the resources to experiment. Is it failure of the services mutually to support one another? Then the answer is coordination. Is it more jobs and higher wages? Then the answer is economic development.

Implicit in the community approach are the consequences of the failure to plan for maximum use of existing resources, the failure to establish goals to fix priorities, and to focus on these priorities. As problems of the poor are defined, and suggestions for action are set forth, the absence of planning and coordination becomes evident. The emphasis of existing programs on symptoms rather than causes is criticized.

There is much truth in this hypothesis, but also much naiveté. A brief look at the problems of poverty in the community, and the complicating factors lying beneath the surface of community life, helps make the dilemma apparent.

\section{A. The Problems of Poverty in the Community}

When the Fund was established in the summer of 1963 , its first action was to define the dimensions of poverty in North Carolina. The enormity of the task the Fund had undertaken was reflected in the cold statistics which laid out the extent of low income, of inadequate education, of poor health and poor housing and delinquency. A review, without necessary order of priority, of some of the things we noted then and continue to face helps to clarify the dilemma of a rural state attempting to lift itself by its bootstraps into the mainstream of American life. In a time of a rising national economy and a rising gross national product, of declining unemployment, we find:

(I) about one-third of all North Carolinians living at an income level inadequate to provide a decent standard of living;

(2) rising unemployment in many low-income, particularly rural, areas while the national level decreases;

(3) increasing unemployment for non-white families while that of white workers decreases, and a wide range between the median income of white families in urban and rural areas as compared with non-white families;

(4) an increasing gap between the wages of the lower one-fourth of the popula- 
tion and the remaining three-fourths, a gap that last reports suggest may have stopped widening but which is not yet narrowing;

(5) the threat of industry to bypass some North Carolina cities on the ground that there is no available labor force. (The fact may well be that there is no reservoir of the skills needed by industry, and in a few urban localities the labor force has been drained dry. In the state as a whole, however, there are thousands and tens of thousands either without a job or earning wages insufficient for adequate food, clothing and housing. And too many of these are Negroes who have heretofore been systematically denied access to skilled jobs);

(6) jobs going in many cities of the Piedmont, while in other parts of the state men who want to work have no jobs because the machine has made their labor on the farm obsolescent;

(7) despite the rate of industrialization in this state and the relatively high percentage of manufacturing jobs, North Carolinians earn less in average weekly wages than workers in any other state;

(8) for every person unemployed in North Carolina, between five and six employed work less than forty weeks during the year, lending some explanation to the information on inadequate income;

(9) about 400,000 adults twenty-five years of age or over who have less than five years of schooling, and almost a million who have less than eight years of schoolingat a time when industry is asking for a minimum of eight years of education and prefers a high school education;

(xo) thousands of young men and women continuing to drop out of school before reaching, much less finishing, high school-when a high school education is an imperative in an industrial society;

(II) two out of every five housing units in North Carolina classified as inadequate, obsolete, or lacking essential facilities such as plumbing;

(I2) continuing evidence of the inadequacy of health, welfare and other services to meet the needs of the poor-evidence in the form of hungry children, families suffering from multiple ravages of disease and despair;

(13) the barriers on every hand which have denied to the Negro the full benefits of society and, in denying opportunity, have helped keep a disproportionate number in the "cycle of poverty";

(I4) evidence that the poor continue to have the largest families and that, particularly in the Negro community, the head of household tends to be the mother;

(I5) the continuing, if somewhat declining, rate of migration to urban centers of the North and Middle West, including not only those who leave because they find opportunity elsewhere but those, unprepared for urban life, who hope unrealistically to find greener pastures elsewhere.

The list could go on. We knew that, however appalling the evidence, progress 
could not be made by focusing on any one problem. As Michael P. Brooks, Director of Research for the Fund, observed in 1963 :

Poverty exists for a number of reasons, and elimination of any one of these reasons will not in itself eliminate poverty. Inadequate education, low or nonexistent income, limited job opportunities, dilapidated and overcrowded housing, poor physical and mental health, and inclination toward delinquency and crimethese and many other characteristics of poverty both cause and are caused by each other, interacting in a manner which renders it virtually impossible for the disadvantaged child, adult or family to break out of the "cycle of poverty." It is essential, therefore, that any attack on the problem of poverty must be comprehensive, bringing the forces of state and community action to bear on all the characteristics of the problem. ${ }^{2}$

As we looked at the problem of poverty, the children and the parents of poverty, we could best pose for all North Carolinians the simple question: How can we in North Carolina reverse trends, motivate people, re-orient attitudes, supply the education and the public services and the jobs that will give all our people the chance to become productive, more self-reliant, and able to compete in the complex but dynamic, exciting but perilous world of today and tomorrow?

\section{III}

\section{Shortcomings of the Community Action Approach in the "War on Poverty"}

In the fall and winter of $1963-1964$, the Fund asked for proposals for demonstration projects from each of North Carolina's one hundred counties.

When Fund staff and board members, encouraged by the response of sixty-six of the one hundred counties to this initial statement of the community action program, sat down to review the fifty-one proposals received, some of the limitations of the community action theory began to be evident. Making allowances for the short length of time provided for the preparation of proposals, it was still clear that communities in North Carolina had not generated many truly creative ideas for dealing with the problem of the poor. It has been no particular source of gratification, though perhaps one of relief, to find that the state and its communities were not unique in this respect.

The coming of the Economic Opportunity Act, and the other legislative milestones on the road to the "great society," interrupted the effort of the Fund to encourage the eleven communities selected for Fund suppport to go back and carry out a more realistic planning process with the help of consultants. No board member could conscientiously spend private dollars for experimental programs when public dollars were available for the same purposes. Instead, the board decreed, the Fund should help the state and its communities take maximum advantage of the

\footnotetext{
2 The North Carolina Fund: Programs and Policies io-i i (zg63).
} 
new resources-now on a community-wide basis rather than on a more limited demonstration basis.

In that first year of an approach to an experimental and demonstration program, and in the succeeding year or more of efforts to help communities take maximum advantage of new federal resources, the shortcomings and complexities of the community action approach have become more evident. Some of these shortcomings are beyond the power of any community to deal with without help from state and federal levels; some of them are built into the community process.

\section{A. Confusion in Objectives}

Despite this nation's declared all out "war on poverty," one thing is clear from the experience of less than two years. The legislative programs enacted by Congress are not at all clear on the objectives of the "war on poverty." In effect, there is a confusion of goals, and because of the confusion of goals there has been a significant confusion in the aspirations and expectations of the poor. For example, the poor as defined by inadequate income fall into several classifications; and many of those who are most poor are not able to increase their income to an adequate level of living through their own efforts. These groups include the aged, the permanently and totally disabled, and young children in families qualified for aid to dependent children. All of these poor live on grants which are demonstrably not enough to provide the minimum standard of living which we are attempting to reach. The grants merely provide for a marginal existence; and, particularly for young children, this marginal existence may build in for the rest of their lives those factors which result in poverty.

Another interpretation of new and existing legislation is that we can best attack the problem by more adequate services. While the need for more educational, health, welfare, and other services must be acknowledged, there clearly is doubt whether services alone meet the needs of those living in poverty-particularly those services that cannot result in increased employment or income. Thus, while services may help people face some of their problems, an increased package of services does not necessarily assure an end to poverty.

Another goal which underlies many of the programs in the "war on poverty" is the opening of opportunity structures for young men and women and for adults displaced from employment or adequate employment by the effects of automation and rechnology. This is clearly the objective of Job Corps, Neighborhood Youth Corps, various manpower programs under both the Economic Opportunity Act and the Manpower Development and Training Act of $1962,{ }^{3}$ and the work experience programs provided under title five of the Economic Opportunity Act. ${ }^{4}$ While these programs are aimed at helping people overcome their inability to compete through

\footnotetext{
${ }^{3} 76$ Stat. 23, as amended, 42 U.S.C. $\$ 257 x-620$ (I964).
}

$\checkmark 78$ Stat. 527,42 U.S.C. $\$ \$ 2921-23$ (I964). 
education and skill training, they do not assure that there will be a job on the other end of the pipeline. They do not insure that the training provided is for skills that will be in demand. And even if the skills lead to jobs, there is no assurance that the jobs will pay a wage calculated to lift the family or the individual out of poverty. Some critics have questioned whether the continued existence of millions of jobs that do not qualify for the minimum wage can ever permit us to lift a significant portion of our population out of poverty, particularly when the minimum wage itself is not sufficient to meet the income required for the minimum standard of living we seek.

Some provisions of the Economic Opportunity Act, particularly those requiring the "maximum feasible participation"s of the poor, suggest that motivation is the problem and that we will not secure motivation until we either make our class structure more open and Alexible, permitting an increasing number of individuals and families to move into the vast middle class, or unless we strengthen and expand the democratic process itself at all levels, so that all our people can play an active part in the shaping of their own, and the nation's, destiny. This latter approach suggests that our service state is not providing the services that the poor themselves define as necessary or needed, and suggests that we need an immediate re-evaluation of our society and the philosophy under which it attempts to help those who lack the income or education to help themselves.

Obviously the formulation of goals at any level is difficult. Congress must question whether public opinion would support more precise formulation of goals. Furthermore, the inertia of old programs and the demand to get new programs under way make careful formulation of goals at any level difficult. But confusion in goals leads to confusion of expectations. And unless we have specific goals, it is going to be difficult for the "war on poverty," as it is carried out at local levels, to meet the full range of expectations. Frustration of expectations can be as dangerous to the success of this war as inadequate achievement of well-defined goals.

\section{B. The Problem of Approach}

Even if there were clearly formulated goals, we would have a serious problem because of differences of opinion in how to approach those goals. And the problem of approach has many facets, not just one.

For example, there is the dilemma posed by the language of title two of the Economic Opportunity Act itself. ${ }^{6}$ The concept of mobilization of services assumes that there are those who have the professional training and commitment and understanding to give the help and assistance to the poor which the poor themselves cannot provide. On the other hand, there is the concept, one of the cardinal American virtues of self-help, that given the opportunity, every individual can find ways in

\footnotetext{
${ }^{5}$ Sec. $202(a)(3), 78$ Stat. 516,42 U.S.C. $\$ 2782(a)(3)(x 964)$.

${ }^{8} 78$ Stat. $5 \mathrm{I} 6,42$ U.S.C. $\$ \$ 278 \mathrm{I}-83 \mathrm{II}$ ( 1964$)$.
} 
which to help himself. Related to this concept is the concept of "the maximum feasible participation of the poor," which suggests that our system of services discourages self-help, that the poor themselves must be involved in the definition of problems and the implementation of programs in order to find the ways in which society can open up avenues through which the poor can move to greater selfreliance.

At another level, we have another dilemma. The concept of mobilizing community resources to focus on the problems of the poor at the local level conflicts with existing methods for dealing with these problems. Existing bureaucracies, which we can lump together as the various state and local agencies and professional groups which have traditionally dealt with problems of the poor, have characteristically been concerned with only a single segment of the poverty problem as it affects individuals; and each discipline-be it education, health, welfare, or recreation-feels that it has understandably acquired a vested interest in how to deal with that segment of the problem with which it has had experience. These professional people find it difficult to react when they are asked to participate in a process wherein the community, the family, and the individual are to be looked upon as a whole, rather than as fragmented entities. Because the credentials of the person doing the asking are occasionally suspect, and because the agency official has a stake in protecting the significance of his graduate degree and his position in the agency, the reaction of the bureaucracy is often negative. The community action organization claims it wants to coordinate the efforts of the bureaucracies, which, in turn, sense this as a threat to their autonomy. The community organization claims that it wants to start new programs; the bureaucracies respond that they themselves would have undertaken such programs long ago were it not for their lack of funds and statutory authorization. These agencies say "Give us the money, and we will run the program; we, after all, are the 'professionals." "

Thus, we not only have the problem of whether we rely on professionals or the poor, but we also have the problem of which professionals. We have the problem of how to introduce a single comprehensive process for the planning of human resource development into an arena already characterized by a variety of planning processes, each with its traditional, carefully-guarded boundaries.

There is still another facet to the question of approach. While this problem is central to the problem of complexity noted below, it also relates to the basic philosophy of the federal system. Although most of the new legislation encourages and requires local community initiative in the definition of needs and ways to meet needs, there is substantial evidence that many administrators of the new programs believe that there are tested ways which should be imposed on communities, whether or not the communities agree. This is reflected in the preference of the Office of Economic Opportunity for some types of prepackaged national efforts. Project 
Head Start is such an example. It was easy to define; it was easy to administer as a uniform program. But there is lack of evidence that a uniform approach to programs for preschool-age children is the best way to meet the very real needs of those children who come from poverty families.

\section{The Problem of Complexity in the Federal System}

Underlying all the problems in the "war on poverty" is a concern for the adequacy of the combined public and private systems that are a part of a functioning democracy.

Our nation of nearly 200 million people is committed both to free enterprise and to government as advocate of the public interest. We do not expect-and certainly do not want-governmental planning and efficiency which theoretically would best utilize our resources, but which, practically speaking, would result in inertia, slavery to a system, and a totalitarian role for federal government.

Serious questions are being raised, however, and are implicit in several pieces of new legislation, as to whether existing governmental and private systems are producing the results that a free people should expect. The question is raised whether a democracy can afford poverty for one-fourth of its people, a poverty that infects the social system and builds in the concept of a disaffected minority.

When we look at the organization of this country, we can identify several operating systems which affect the status of individuals. There is the economic system, in all its variety and complexity, which keeps the wheels of production and distribution of goods in motion. There is the system of government, a federal system, which operates in different ways in fifty different states to serve both national and local concerns. And there are other systems, albeit more informal ones, which provide the mechanism through which both public and private agencies achieve local and national objectives. From this point of view, we can define systems of informally related agencies which deal with such problems as land development, transportation, communication, urban renewal, education, provision of health and welfare services, provision for housing, and so on. We can also, from another point of view, identify the multitude of governmental and private agencies which together focus on the community, whether defined in geographic terms, in terms of areas limited by local governmental boundaries, or defined on a regional or state basis.

It can be said that, however we define the responsibilities of government in cooperation with the private sector, these systems are not doing the job when onefourth of our population lacks the income, the education, the employment, and the opportunity to participate in the wealth of a free society.

Here again the existing "great society" programs complicate rather than clarify goals. At one and the same time they ( $x$ ) encourage further development of the federal-state-local approach to the provision of services such as education, and (2) encourage federal-local relationships which squeeze out the potentially valuable and 
essential mechanism of the state. This is particularly confusing when the concept of "mobilization of resources" under the federal-local program in the Economic Opportunity Act requires coordination with significant services which are primarily state-administered or state-coordinated.

Thus, we have a series of basic questions. If the "war on poverty" is to be successful, we need to redefine the proper roles of several levels of government. With a substantial increase in federal assistance for locally- and state-administered programs, can the federal government provide a framework for action which is appropriate for all states and localities? To what extent must the federal government adopt common restrictions and regulations which limit local initiative but without which the intended benefits may not reach those who need to be helped? Or can the federal government coordinate its own policies and services, emanating from several major departments, in such a manner as to permit rational planning at state and local levels? There is no source of greater frustration for the state or local official than to try to determine a policy consensus for programs which involve two or more federal agencies.

Similarly, questions must be raised about the role of the state and the role of the local government.

The state does have a strong role to play. Ideally, it can serve as a countervailing force against the rigidity of federal agencies, on the one side, and against the occasional parochialism and short-sightedness of local governments, on the other side. The state can provide expanded technical assistance and expertise to communities which need it. It can increase its sensitivity to problems as they are defined locally, and can formulate programs and policies accordingly. It can develop experimental or demonstration projects in problem areas which transcend the boundaries or resources of a single community-for example, in the areas of manpower and economic development. It can pioneer in the usage of sub-professional personnel in service agencies. There are, in short, a number of potentially valuable functions for the state. Whether or not the states will carve out significant roles for themselves-and in fact, whether the concept of federalism is to remain viable in the face of contemporary problems-remains to be seen.

There are also questions to be asked about the role of local government in the "war on poverty." Does it have the power to coordinate an effective attack on the problems of low-income families? Can it bring to bear on local problems the information necessary to analyze and plan? Can it find, within its own boundaries, the expertise needed for the design and execution of effective programs? While the nation's metropolitan areas undoubtedly have this expertise, there are hundreds of small cities and towns which do not. How-if at all-can the necessary skills be brought to bear on such communities in a manner which is consistent with the principle of local autonomy? 
And finally, how is local government to respond to the charge that its antipoverty programs must indeed be based on the democratic process-that is, that the poor must be given an active role in programs aimed at improving their circumstances?

In terms of the combined public and private systems, such as manpower and economic development, and housing, and education, there is a demonstrable need for more careful evaluation of how these systems operate, of how they succeed, and of how they fail to achieve desired results. There is also need for a continued dialogue between governmental and business leaders and representatives of the poor on how best to achieve results in terms of jobs, homes, and educational opportunities. But these cannot be discussed without the availability of more information defining the boundaries of the problem. At the state and local, as well as at the federal level, we need more information on which to base further definition of the problems, and thus the policies, that today are not working but which must be changed.

We also need a setting in which there can be innovation in development of the things we try and subsequent evaluation of the techniques chosen. There is a limit to the development function of government, and of the universities, as they have dealt with the problems of human resource development. We need to find additional institutions, similar to the Learning Institute of North Carolina, which can define new solutions and try out new ways of dealing with the problems of people.

\section{Role of the Poor}

The Economic Opportunity Act of 1964 not only emphasizes mobilization of resources to meet the needs of the poor; it also requires "maximum feasible participation" of the poor in planning and administering community action programs. ${ }^{7}$ In establishing community action organizations under the Economic Opportunity Act, there is a requirement that these organizations be broadly representative of the entire community, including representation from business and labor, from public agencies and private agencies, from representatives of minority groups, and from representatives of neighborhoods and groups where the incidence of poverty is highest. In administering programs, the employment of the poor in sub-professional roles is encouraged, both as a source of employment and as a means of reaching more successfully the poor.

These latter concepts are new to most of us. As Fortune magazine has pointed out, ${ }^{8}$ this concept is one of the really new things in the "war on poverty." It does not seem to make sense to many people, for how can the poor, who are the least able to produce, help plan and coordinate and administer complicated services? The answer lies in understanding history and understanding people.

First of all, our nation has traditionally acted for the poor. We have decided what they needed. We have expected them to think as we think, to act as we act.

\footnotetext{
${ }^{7}$ Sec. 202 (a) (3), 78 Stat. 516,42 U.S.C. $\$ 2782$ (a)(3) (1964).

${ }^{8}$ Ways, Creative Federalism and the Great Society, Fortune, Jan. 1966, p. I21.
} 
And if all that our scientists tell us is true, we were totally and abysmally wrong. We not only misunderstood them. We lost their respect and confidence. In particular we lost the respect and confidence of minority groups.

If the poor lack respect and confidence for government, and for community agencies, how can that confidence be restored so that there will be the desire to get an education, the motivation to work, and the assurance that work and education will pay off in jobs that pay good wages? The assumption of the Economic Opportunity Act is that, initially, respect and confidence can best be restored by bringing representatives of the poor and the poor themselves into the planning of programs aimed at the poor, by letting them speak up concerning what is needed, by giving them the assurance that comes from participation. Does it work? It is hard to say concretely, but all of the evidence is that it does work, and is working better as our experience increases.

The Los Angeles riots offer fresh evidence that, whether we who are not poor like it or not, the poor are going to participate in American life. The question is, how will they participate? Destructively, or constructively? The answer is obvious, and the Economic Opportunity Act provides, indeed requires, that the poor be involved in our planning for the future.

This involvement with and for the poor may open our eyes to a lot of things, correcting a lot of myths about the poor. For example, the experience of the Fund to date, and the experience in North Carolina, has responded concretely to many myths about the poor, and particularly the Negro poor.

I. It was said that the illiterate did not want to learn; but thousands have responded everywhere throughout the state to the adult basic education program. The sad feature of this program is that there is not nearly enough money to meet the demand.

2. It was said that the poor would not leave their homes, whether on an eastern farm or a mountain cove, to seek employment. But a Fund-sponsored mobility program demonstrated that the poor, even the illiterate, would move wherever opportunity in the form of employment and training was offered. And the record of adjustment to urban life and manufacturing jobs was good. Likewise the experimental manpower development program in six eastern North Carolina counties demonstrated that the poor, the unemployed, the displaced want to learn to read and write, to learn a vocation, to find employment.

3. It was said that the poor could not effectively participate on community action boards and were not interested in poverty programs. But they have demanded the right to participate, they have articulated their needs and priorities, and it has given the poor, and particularly the Negro poor, the type of confidence in the local antipoverty program without which success would not be possible.

In too many cases, however, the willingness to respond is greater than the ability 
to respond. If motivation can result from the realization that long-locked doors are being unlocked, that the opportunity to take part in community affairs can lead to programs that better meet the felt needs of the poor, that the community's helping hand is not linked to conditions which deny self-dignity-if such motivation can result, then more exploration must be made of the avenues by which this motivation is stimulated and assisted.

A second danger, a critical one, is that once opportunity has been promised, the gates may close again-for lack of funds, as in the adult education program, or for lack of jobs, as in all programs dealing with manpower development.

Involvement of the poor has been criticized on other grounds. Some critics have charged that it builds unhealthy social conflict into the community action process, and indeed it can result in conflict where communication is not established. But there can be constructive conflict, where those without a voice gain a voice, and destructive conflict, where those without a voice continue to be denied a voice. The techniques of involvement, of motivation, of community organization, may vary from community to community, but motivation is not likely to come in a community where opportunity to speak, to participate, to find education and employment is not forthcoming.

Although the problems of motivation and opportunity exist without regard to color, it is demonstrably greater in the Negro community, as shown in North Carolina in the community action projects in the East and Piedmont. There is a continuing need for a more open dialogue between the races in these communitiesfor dealing directly with the need for the education and jobs and services that can both lead out of poverty and lead to healthier community-wide relationships. The Fund was founded to deal with poverty wherever it is found, but it must also recognize the problem of equality of opportunity-in whatever sphere-for the Negro will not take part in these programs unless he has confidence that he is part of it and that the program is color blind.

\section{E. The Problem of Time and Experience}

The Fund staff has had extensive experience during the last two years with the limitations of crash planning, with administration of complex new programs by inexperienced personnel, and with lay leadership unequipped to cope with intricate problems. Time has not allowed careful planning, adequate training of personnel, or proper negotiation and coordination of related agencies at state and local levels. The system of professional education in the United States simply has not turned out people with the experience and breadth of understanding to move easily into top administrative positions in community action programs. And there is no agreement on what combinations of education and experience are best designed to equip people for these positions.

Limitations of the planning process will show up as disappointing results in 
programs once thought to be promising; similarly, the impact of inadequatelytrained personnel will become more marked as the number and complexity of state and local programs increase.

It is highly essential that continued emphasis be placed on establishment of programs in the university system, and within the community college system, to insure better professional education, better education for sub-professional careers, and better education for citizens and administrators undertaking complicated tasks without prior experience.

\section{F. The Problem of Public Understanding}

As a general rule, the public fails to understand the problems of poverty, and understands even less the problems of dealing effectively with the causes of or solutions to poverty. Lack of understanding may be the result of lack of information, in part of bias and prejudice, or of difference of opinion in interpreting the operation of our society or how to deal effectively with acknowledged problems. Too many new problems introduced too quickly have magnified the problem, so that there tends to be more confusion as a result of the new program than when emphasis was simply on the problems alone.

\section{IV}

\section{ROLES OF THE FUND}

In seeking to define both the science and art of the possible in this context of community, and under crisis or crash conditions, the Fund has adapted its choices to a range of needs, a range of priorities, a range of conclusions. It was early clear that the simple grant-making approach would not result in bringing about the kind of change that was necessary in a community. The problems were too complex; the resources of trained manpower and of civic leadership were too scanty; the points of possible impact were too numerous.

. The staff and board of directors had another problem to face. They had their own image of what the Fund was supposed to do and what it could best do. Likewise, others throughout the state had a specific image of what the Fund might do in the "war on poverty." State and local agencies looked upon the Fund as a source for financing new services but in continuation of old patterns. The new-born community action projects looked upon the Fund as a bank account for resources and money not available from Washington. Some representatives of the poor looked upon the Fund as an advocate. Educational institutions looked upon the Fund as a source for additional research. All sorts of people made it clear that they had the answers to the problems of poverty, the simple answers that could cut through the complicating and frustrating factors described above. There was even the serious proposal that the Fund use all its resources to bankroll a new industry, for only with new jobs could the problem of poverty be solved. 
Although community action became a national policy in the summer of 1964 , rather than a simple experimental approach, the Fund did not abandon either its own emphasis on or concern for what might be achieved in local communities. The belief continued that a central change must become a reality in the community if it is to be a lasting change.

Focus on the community as the arena for change has many advantages. First of all it is in the community that we gain an understanding of the human perspectives of poverty-the impact of the environment, of lack of education, of lack of income. Likewise, it is in the community that we see at first hand how all of the resources of the federal system are now employed-some successfully, some unsuccessfully-and we gain insights into these weaknesses-insights that need to be fed back to state and federal levels. We see the limitations of, as well as the potential for, coordination. We see the gaps in essential services, the absence of rational planning, the cross purposes with which many agencies and groups in professions work.

It is also in the community that we see the democratic system at work, sometimes succeeding, sometimes failing. It is in the community, along the slum streets and down the dusty roads of the rural areas, that we come to know the poor, to discover their attitudes toward the establishment as enemy, to discover how little middleclass America is sensitive to the dreams and the aspirations and the capabilities of those who have fewer resources but no less humanity. And it is in the local community that we see how governmental policy can be used to help, or frustrate, the poor.

Thus the Fund's focus continues to be the community as a whole, and the poor in the context of the community. This focus does not exclude Fund activities in relation to the essential roles of the state and federal government, or educational institutions, or of other statewide and national organizations. In many important respects policies and programs at these levels govern community action and response. But the emphasis, the focal point, is on the poor in the context of the community in which they live.

\section{A. The Fund in the Community}

Before the Economic Opportunity Act became a reality, the board of directors of the Fund had assured the community action programs (those first selected for Fund support) a small annual grant for a period of four years to permit each of the communities to organize, employ a competent director, and begin the overall planning process. These grants assured each community the funds to compete successfully for qualified executive staff; and because they were staffed before the Economic Opportunity Act became a reality, each of these projects was able to get a head start on other communities not similarly organized. 
In addition, the Fund provides to each such program technical assistance in the mobilization of resources from all levels of government, development of proposals that require technical training not available at the community level, and pilot grants for initiating developmental programs.

As community action programs have grown rapidly, without patterns or a reservoir of trained manpower from which to draw, stresses and strains have appeared in the administrative fabric. This has necessitated special technical assistance in administrative organization, financial accountability, personnel administration, and in-service training.

From the beginning the Fund has been concerned that the poor themselves be involved in the development of community action programs. With the passage of time, and a better understanding of the problem, the Fund has concluded that one of its major objectives must be to help the poor show they can be effective not only in identifying their own needs and opportunities, but in participating in the decisionmaking process of the entire community. In support of this objective the Fund provides technical assistance to community action agencies in the techniques of involving the poor, in preparing board members from low-income neighborhoods for effective policy-making responsibilities, and in promoting dialogue between the traditional power structure of the community and representatives of the poor and of minority groups.

In some cases, moreover, a good and workable idea comes up for financial support of a character not available from the federal government. One community action agency covering four counties in the Appalachian mountains asked for a grant to permit it to offer incentive payments to remote mountain communities which could organize, identify local needs, and meet those needs with the aid of a little money. The initial reaction to this program is very positive.

\section{B. Fund Programs in Support of Communities}

In some cases, however, financial or technical support to community action agencies is not enough or cannot be calculated to meet priority needs.

In the summer of 1964 the Fund recognized the critical shortage of trained manpower capable of dealing at first hand with the technical problems arising in the community action agencies. As a stopgap measure, the Fund proceeded to organize and support a program for training young men and women interested in community action operations. With a small grant from the Department of Labor's Office of Manpower, Automation and Training, the Fund brought together its first group of community action technicians in August of 1964 . These fifteen young men and women were drawn from the North Carolina Volunteers (an experimental program in the utilization of college student volunteers during the summer months in community action programs), Peace Corps returnees, and state government interns. 
Following a period of five weeks of residential training, these young men and women were assigned for an additional three months period to community action agencies. Later they entered regular employment with these agencies.

The program was so successful that a grant was secured from the Office of Economic Opportunity to continue the program. Two more groups were trained during 1965 , and the grant has been renewed to enable continuation of the program during 1966.

Section 603 of the Economic Opportunity Act ${ }^{0}$ provided for the recruitment and training of VISTA volunteers for assignment to antipoverty programs. Since each of these volunteers had to receive advance training before assignment, the Office of Economic Opportunity had to organize crash training programs. At the request of the Office of Economic Opportunity, the Fund entered into a contract for training of the first group of thirteen VISTA volunteers recruited under the Economic Opportunity Act. The training program was successful, and after a second group, the Fund entered into a contract to train six additional groups. Although these volunteers have been assigned all over the country, a significant number are serving in North Carolina communities today.

The Fund also took under contract the training of twenty-five community services consultants for the State Board of Welfare under a special grant from the Department of Health, Education and Welfare. These consultants were assigned to twenty-five communities for the purposes of helping coordinate the services to meet the needs of low-income people.

The combination of these training activities focused attention on the need for a training center in the state, for training at the professional, sub-professional and indigenous levels. Rather than institutionalize its training function, the Fund asked the University of North Carolina to explore the possibilities of establishing a center that could coordinate the resources of all university schools and departments to provide training at all levels in the new antipoverty programs. The University responded positively to this request, and had established a committee to explore how such a center might be established when the Office of Economic Opportunity asked that the University of North Carolina accept a demonstration grant for creation of such a center. The University is one of four in the country with such a grant. The new Center for Community Research and Services has been established at the University of North Carolina at Chapel Hill with a grant from the Office of Economic Opportunity supporting initial staff to help coordinate and develop training programs and programs of consultation. Because the University was interested in a total, balanced program which would include research and evaluation, the North Carolina Fund made a grant to the University to support the research component until additional funds for permanent support of this component can be

\footnotetext{
${ }^{\circ} 78$ Stat. 530, 42 U.S.C. $\$ 2943$ (1964).
} 
located. With establishment of the Center, the Fund hopes that it can phase out its general training functions.

One of the major problems in the "war on poverty" is the need for introducing change into professions and institutions responsible for essential services to lowincome target groups. Often traditional professions regard grants from foundations as the excuse for "more of the same," and they are not willing or anxious to listen to the attitudes of the poor and to experiment with the types of changes which would better reach the poor. For this reason, it is often difficult to identify proposals from such agencies which promise true innovation. From its developmental funds the Fund is in a position to make a number of grants aimed at institutional change; and it is eager to do so.

In areas where there are no agencies presently providing essential services, or coordinating a range of related services, it is sometimes difficult to arrange for proposals for innovation. In such cases, the foundation may be faced with the decision to sponsor and administer directly a demonstration project itself. One such example is the manpower development program undertaken by the North Carolina Fund in six eastern North Carolina counties, aimed at the problem of identifying and helping to improve the employability and therefore the income of rural lowincome families.

One of the techniques successfully used in this program is employment of men and women from the rural community as field workers to find and identify those heads of household qualifying for the program (by having an annual income of less than $\$ 1,200$ per year or unemployment for six months or more). From the results of these exhaustive surveys by the field workers, counselors review the opportunities available in vocational training or on-the-job training for those eligible, and arrangements are made to provide the type of training which is appropriate.

While the results of the program are beginning to be impressive in terms of persons trained and placed in employment, the initial significant factor was that the field worker, a sub-professional, was having success in finding and motivating men and women of all races to seek additional opportunities. They were finding that these men and women, acquainted only with the farm, poorly educated, displaced from the farm by automation, unfamiliar with the institutional resources of American society, were anxious to receive training, to receive opportunity, and to work. The field worker has been an essential factor in helping these men and women find opportunity and take advantage of services and resources to which they were entitled but which were unavailable to them.

The results of this manpower program have been used by community action programs throughout the state to help define new ways of approaching the problem of manpower development. 
From the very beginning in 1963 , the Fund has been concerned with evaluating its programs. It has also been concerned with seeking out the information on which to build good programs.

What do poor people think about? What are their values, their attitudes, their aspirations? A survey of low-income families, designed to help answer these questions, is one project of the Research Department of the North Carolina Fund. The Fund initiated this survey during the summer of 1964 , and a year later received further financial support for it from the Office of Economic Opportunity. The Research Triangle Institute, a non-profit research organization located near Durham, contracted to do the survey's field work, which included interviews with around I3,000 families in the eleven Fund-related communities. After the field work was completed, late in December of 1965 , the Fund's research staff began data analysis, which is still in process.

This is one project of the research program, the overall purpose of which is to evaluate the effects of Fund and Fund-related activities. Such evaluation serves both to inform the funding agents of the value received for dollars spent, and to furnish guidelines for the improvement of existing and future programs.

Evaluation efforts involve two dimensions. The first dimension includes three levels of evaluation: individual projects, such as pre-school centers; each community action program in its totality; and the impact of the Fund on the state as a whole.

The second dimension includes two foci of evaluation: the program product, or impact-that is, the measurable changes which occur, as a result of community action programs, in the concomitants of poverty (low income, unemployment, inadequate housing); and the program process-the social and political aspects which influence the results of a given community action program.

One way to evaluate the program process is to analyze the relationship between a community action program and the community-including its social, political and economic components-in which the program takes place. Aided by a June 1965 OEO grant, the Research Department undertook this analysis.

In fact, the research functions of the Fund have been limited only by lack of staff and lack of financial support. Although the Fund would have preferred to have made available to each of its community action programs a full and qualified research staff, neither the manpower nor the money was there. It is hoped that the research staff of the newly established center at the University of North Carolina will be able to provide assistance to community action programs in effective evaluation of their component programs.

Finally, it became increasingly clear during 1965 that many people did not understand the antipoverty program. A successful mobilization of resources in a community to attack the problem of poverty requires widespread public support, and the Fund found itself called upon to provide aid to the community action projects in using every possible means of communication to explain what was being 
done under antipoverty programs and why. The initial efforts in this respect were so successful that the public information staff of the Fund has been increased, additional support is being given communities, and staff has been employed to work through civic clubs and conventions, and to use all other means to bring to the people of the state a better understanding of the purposes and objectives of the antipoverty programs.

\section{Fund Activities at the State Level}

It bears repeating that the Fund's emphasis and focus on the community has not been taken with blinders on. The job cannot be done at the community level alone, particularly in this era of efforts to establish "creative federalism" and to define the most effective roles for state government as well as the federal and local governments.

From its very beginning, the Fund has been closely related to the efforts of all state agencies to play a constructive role in the "war on poverty." Again, the ways in which the Fund works with state agencies depend upon needs and priorities at any given time.

For example, in the early months of the "war on poverty," the Fund was able to provide technical assistance to the state government, to educational institutions, and particularly to the state's new economic opportunity staff concerning antipoverty programs, the mobilization of resources, and new approaches to the delivery of traditional state services.

There have been grants to state agencies. At the time the Fund was established, $\$ 2,000,000$ of the resources made available by the Ford Foundation were earmarked for a grant to the State Board of Education to experiment with new ways of teaching the first three grades of school. The comprehensive school improvement project has been a major effort of the State Department of Public Instruction in adjusting to new demands in school systems; and it has enabled school systems throughout the state to anticipate and prepare for the opportunities afforded under the Elementary and Secondary Education Act of $1965 . .^{10}$

One of the first acts of Governor Moore in I965 was to establish the State Planning Task Force to help coordinate the resources available from federal programs for administration within the state. A grant was made to the State Planning Task Force to enable it to include a human resources coordinator on its staff. A similar grant went to the Task Force to help support a staff position to develop a low-income housing program within the state.

The North Carolina Fund joined with the University of North Carolina, Duke University, and the State Board of Education in support of the Learning Institute of North Carolina as a new and critical agency for administering research and demonstration programs aimed at improving the system of public education in

\footnotetext{
${ }^{10} 79$ Stat. 27 (codified in scattered sections of 20 U.S.C.A. (Supp. 1965)).
} 
this state. A later grant went to support Youth Educational Services, an effort by a committee group of college students to introduce effective tutoring programs in both urban and rural areas in North Carolina.

As in the case of the communities, every opportunity for innovation and change could not be handled by an existing agency. In the absence of another agency able to administer the mobility program, for example, the North Carolina Fund accepted a grant from the U.S. Department of Labor to conduct the experiment.

\section{The Fund as Critic}

In all of its processes of learning more about the problems of poverty in North Carolina and the complicated reasons why it is so difficult to break people out of poverty, the Fund staff and board have become aware of the critical role that certain systems-such as education, housing, and manpower development-play in determining whether opportunities can be opened to the poor. The systems of local, state and federal agencies, and of private agencies, involved in the administration of these critical services and in making them meaningful to the poor are so critical to the success of the antipoverty program that they bear separate study as systems. The Fund has established several committees composed of board members, staff members, and citizens from across the state to take a look at some of the critical systems affecting antipoverty programs and to identify the weakness in those systems that, if corrected, can help bring success to the "war on poverty."

\section{CONCLUSION}

With a little more than two years and about half of its initial development funds to go, The North Carolina Fund is engaged in a continuing examination, with board and staff members, of needs, priorities and problems affecting poverty in North Carolina. It is more than ever conscious of the possible, of investing in efforts that will bring long-range benefits to the poor and the communities in which they live. It is conscious of the advantages and limitations of the direct grant (particularly where there is no assurance of financial support once the grant has been spent), of the need to insure that persons and agencies do not come to rely on technical assistance that cannot be maintained past 1968, of the need to build in and build on new programs under institutions that have a continuing life.

Now that communities have gained experience in using the resources available under federal antipoverty programs and related "great society" legislation, the Fund need not be so concerned that these resources be properly used. The patterns of use are being established. Likewise, concern for programs of professional and subprofessional training and for continuing research and evaluation is no longer of the highest priority because of the developing programs at the university.

But persistent and major problems remain on the Fund agenda. Where priorities 
for continuing effort will be determined depends on board and staff action, but the area of action is relatively clear.

(I) There is the problem of finding and supporting articulate leadership from the ranks of the poor, of all races, to insure that the point of view of the poor is fairly expressed.

(2) There is the problem of how to help the poor better define their own priorities and to communicate them to key community agencies.

(3) There is the problem of whether the community action agency, aptly compared to an international treaty organization, can carry out an effective role of helping all community agencies plan, identify, and carry out programs essential to reducing or eliminating poverty and its effects.

(4) There is the problem of whether communities can develop operational planning processes that involve all related service and educational agencies, and involve a representative cross-section of the community.

(5) There is the problem of whether the poorly-educated and displaced can be provided the skills and the opportunity to become productive and more self-reliant.

(6) There is the problem of whether public education can adapt itself to the needs of children from disadvantaged homes so that, as they grow through the school system, they acquire the knowledge and capabilities that can overcome an inadequate beginning.

(7) There is the problem of overcoming the continuing effects of racial bias and prejudice in order to open educational and employment opportunities to Negroes and Indians that are responsive to their needs and aspirations.

The Fund does not have enough dollars to meet head-on any one of these problems. It must survey the possible needs and opportunities, assess the possible consequences, and act in its best judgment. The board and staff have had ample experience in adapting to a changing situation. There is no reason to believe that they cannot continue to do so. And in so doing, it may be that they will define a role for the use of philanthropic funds to help meet the changing needs of a state that will not be limited to antipoverty programs. Poverty is a current national problem, as well as a state problem. As our society grows and matures, new problems will arise. The foundation which can anticipate, define and help a state meet new challenges will have a continuing usefulness. 